УдК 655.3.062; 535.674.3; 534.65.083.6

( Я. В. Зоренко, к.т.н., ст. викладач, Д. О. Сак, магістрантка, НТУУ «КПІ», Київ, Україна

\title{
ПАРАМЕТРИ ВІДЕОСИСТЕМИ КВС ДЛЯ ПРОЦЕСУ КАЛІБРУВАННЯ
}

Встановлено характер впливу основних параметрів відеосистеми КВС на якість відтворення кольору тонових оригіналів.

Визначено оптимальний період здійснення калібрування для конкретного класу моніторів із забезпеченням стабільного кольоровідтворення. Запропоновано перелік рекомендацій для стабілізування процесу калібрування.

Ключові слова: калібрування монітору, профілювання моніторів, колірне охоплення, максимальна яскравість, колірна температура.

\section{Постановка проблеми}

Зважаючи на зростаючу конкуренцію між поліграфічними підприємствами, що орієнтовані на високоякісну поліграфічну продукцію, можна констатувати існуючу потребу щодо впровадження новітніх технологій, які дозволяють спростити і підвищити якість технологічного процесу. Тож застосування технологічних процесів калібрування i профілювання дозволяють значно розширити функціональні можливості виробничого обладнання та зменшити трудомісткість за рахунок прогнозованому кольоровідтворенні оригіналів [1-4].

Технологічні процеси калібрування і профілювання складників комп'ютеризованої видавничої системи (КВС) в додрукарських процесах поліграфічного виробництва $€$ необхідним засобом для забезпечення прогнозованого і стабіль- ного кольовідтворення тонових оригінал-макетів.

Серед основних завдань, які виконуються при калібруванні та профілюванні $є$ узгодження режимів і параметрів роботи складників КВС, а також забезпечення точного кольоровідтворення оригіналу на різних стадіях додрукарської підготовки [1-4].

Одним із головних складників KBC, що найбільше впливає на якість обробки оригіналу $\epsilon$ монітор, або, так звана, відеосистема КВС. Від якості калібрування і профілювання відеосистеми КВС залежить у першу чергу точність сприйняття колірних $\mathrm{i}$ градаційних характеристик оригіналу, а отже і коректність застосування подальших заходів щодо процесів тоно- і кольорокорекції. Здебільше не скорегована відеосистема КВС призводить до погіршення якості друкованої продукції. 
Також, слід зазначити, що із появою різноманітних типів LCD-моніторів, номенклатура яких значно розширилася, а стабільність кольоровідтворення відповідно значно різниться, виникла потреба у визначенні критеріїв оцінки якості цих систем. Тому дослідження режимів калібрування LCD-моніторів $€$ актуальним і на часі.

\section{Аналіз попередніх досліджень}

Аналіз досліджень, присвячених якості сучасних LCDмоніторів [5-9], а також методам та технологіям калібрування відеосистем КВС виявив суттєвий інтерес фахівців до даної проблематики. Так, більшість досліджень [7-9] стосується визначення точності стандартних характеристик сучасних LCD-моніторів, що дозволяє встановити для конкретних пристроїв основні показники якості, а саме рівномірність яскравості та кольору, точність кольоровідтворення та величину колірного охоплення в систеmax «Adobe RGB» та «sRGB». Визначені таким чином показники якості дозволяють встановити, згідно міжнародних стандартів [10, 11], можливість застосування LCD-моніторів у якості відеосистем КВС.

Також, частина досліджень $[5,6]$ стосувалася визначення точності створеного колірного профілю для LCD-моніторів за допомогою різних апаратнотехнічних засобів калібрування та профілювання.

Отже, більшість досліджень стосується встановлення відповідності характеристик пошире- них марок LCD-моніторів щодо вимог регламентованих міжнародними стандартами та ергономічними вимогами, що дозволяє застосовувати їх для тонота кольорокорекції і можливо у якості складового елементу кольоропробної системи. Однак, їх результати не дозволяють встановити оптимальний період здійснення калібрування і профілювання для LCD-моніторів із забезпеченням стабільного кольоровідтворення, що залишається перспективним напрямком досліджень.

\section{Мета роботи}

Дослідження основних параметрів відеосистеми КBC на базі поширених моніторів та аналіз їхнього впливу на якість кольоровідтворення ілюстраційних оригінал-макетів.

\section{Результати проведених досліджень}

В ході проведеного дослідження було застосовано стандартні відеосистем КВC від різних виробників, що застосовуються для додрукарської обробки ілюстраційних оригіналмакетів, а саме LCD-монітори Samsung R530, Samsung SyncMaster 2043, LG Flatron L 194WS, LG Flatron W1942S, Asus W202SR та CRT-монітор з електронно-променевою трубкою Sony Multiscan 520GS Trinitron. Калібрування та профілювання досліджуваних моніторів проводилося за допомогою пристроя «Spyder 2» від компанії Datacolor та відповідного програмного забезпечення - «Spyder2PRO».

Статистична обробка результатів дослідження за кри- 
терієм Стьюдента для підтвердження достовірності експериментальних даних здійснювалася за допомогою програмного забезпечення MS Excel 2003; побудова графічної інтерпретації результатів дослідження Mathworks MatLab 2008.

Відповідно до умов калібрування, здійсненого для досліджуваних моніторів та діючих стандартів [10-12], були обрані раціональні параметри калібрування: колірна температура 6500K; гама 2,2; максимальна яскравість монітора 80120 кд/м²; контраст в діапазоні 50-90\%.

Для порівняння колірного охоплення ( $\mathrm{S}_{\text {c.g. }}$, \%) моніторів було здійснено розрахунок площі трикутника утвореного трьома точками за координатами системи CIE xyY [13]. Причому визначена площа трикутника в системі CIE xyY порівнювалася та інтерпретувалася у вигляді відносної площі колірного охоплення стандартних колірних профілів «SRGB» і «Adobe RGB», які використовуються у моніторах.

В ході дослідження кожен із застосованих моніторів проходив калібрування згідно рекомендацій [10-12], як із вимірюванням центральної ділянки екрана, так і за вимірюваннями умовної площини екрана монітору, який було поділено на дев'ять однакових ділянок (рис. 1). Причому вимірювання здійснювалося як для значень стандартної колірної температури (T, K), так і для значень максимальної яскравості монітора (L, кд/ $\mathrm{M}^{2}$ ).

Вимірювання максимальної яскравості всіх дев'яти ділянок

\begin{tabular}{|c|c|c|}
\hline 1 & 4 & 7 \\
\hline 2 & 5 & 8 \\
\hline 3 & 6 & 9 \\
\hline
\end{tabular}

Рис. 1. Схема умовного поділу площі екрана монітору

площини моніторів після проведеного калібрування, а також визначення на їх основі відносної рівномірності (показника приросту на всіх ділянках порівняно із мінімальним значенням) яскравості $(\Delta \mathrm{L}, \%)$ для всіх ділянок, дозволило проаналізувати розподіл яскравості на площині екрану монітора (рис. 2).

Для порівняння кольоровідтворення досліджуваних моніторів здійснено вимірювання колірних характеристик після калібрування та профілювання та побудова меж колірного охоплення у системі CIE хуY (рис. 3).

Аналіз колірного охоплення, що отримується в процесі калібрування колірного профілю досліджуваних моніторів (рис. 3) вказує на те, що допустимі значення колірного охоплення забезпечуються у моніторах Samsung SyncMaster 2043, LG Flatron W1942S та Asus W202SR.

Згідно розподілу рівномірності яскравості на екрані та колірного охоплення моніторів можна припустити, що збільшений рівень колірного охоплення призводить до зростання рівня нерівномірності яскравості. Так, монітори Asus WW202SR та 


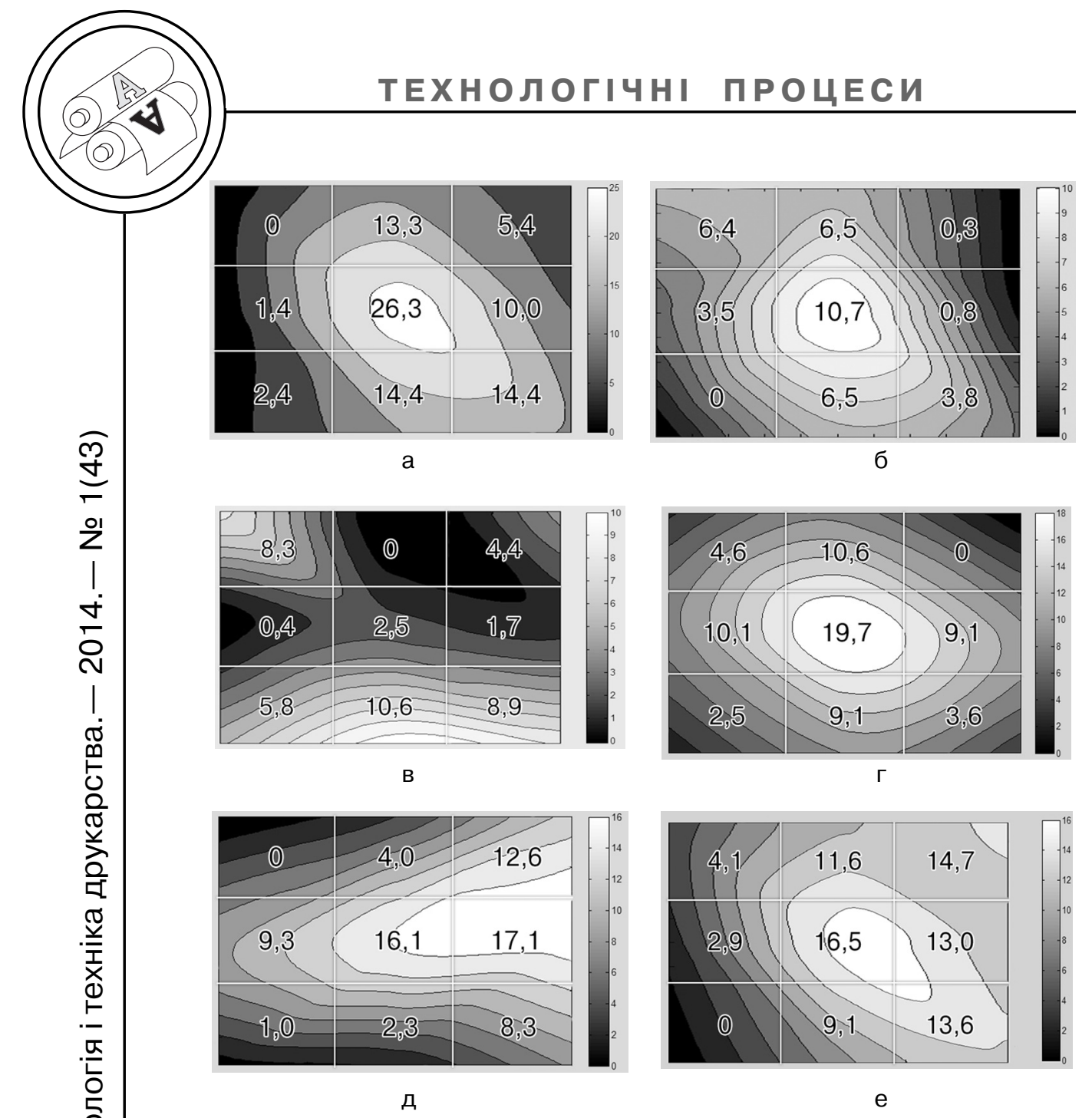

Рис. 2. Розподіл рівномірності яскравості на площині екрану монітора $(\Delta \mathrm{L}, \%)$ : a - Asus WW202SR (LCD); б - Sony Trinitron (CRT); в - Samsung R530; г - Samsung SyncMaster 2043; д - LG Flatron L 194WS; e - LG Flatron W1942S

Samsung SyncMaster 2043 поряд із більшим колірним охопленням володіють більшою нерівномірністю яскравості на екрані монітора. Слід, також, зазначити недостатній рівень колірного охоплення у моніторів Samsung R530, LG Flatron L 194WS та Sony Trinitron, що не відповідає вимогам [11] до їх застосування у якості відеосистем КВС.

З отриманих значень колірної температури для точки біло- го (D65) (рис. 4) можна констатувати, що жоден із моніторів стабільно не відображає колірну температуру. Оскільки на кожній з гістограм епізодично спостерігаються зниження точності $\Delta \mathrm{E}>1$. Загалом, для кожного із досліджуваних моніторів характерні особливості відтворення рівня колірної температури.

Так, для монітору Asus WW202SR спостерігається стри- 


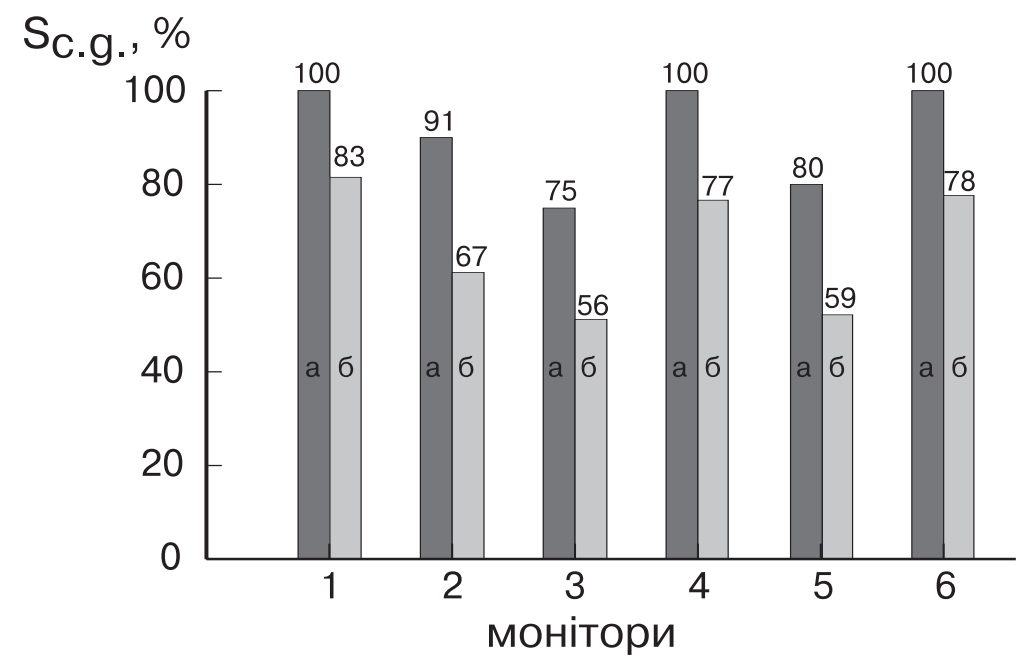

Рис. 3. Колірне охоплення досліджуваних моніторів: 1 - Asus WW202SR (LCD); 2 - Sony Trinitron (CRT); 3 - Samsung R530; 4 - Samsung SyncMaster 2043; 5 - LG Flatron L 194WS; 6 - LG Flatron W1942S; a - колірний профіль «SRGB»,б - колірний профіль «Adobe RGB»

бок середньої колірної температури у перші три дні, а потім підтримується досить стабільний рівень в діапазоні 6700-6800 К, що може призвести до незначного спотворення кольору на зображенні на ділянках синього тону.

Загалом, монітор Samsung SyncMaster 2043, так само як i монітор Asus WW202SR, після 3-4 днів відтворює кольори із незначним спотворенням $\Delta \mathrm{E}<3$, що максимально допустиме за стандартами [10-12] при калібруванні за точкою білого (D65) (рис. 4, a, г ).

Для Samsung R530 (рис. 4, в) спостерігалися значні стрибки колірної температури вже починаючи з четвертого дня. Ceредні значення колірної температури коливалися у діапазоні 6200-6400 К, що призведе до незначного спотворення кольору на ділянках червоного тону.
Інші монітори LG Flatron L 194WS, LG Flatron W1942S та Sony Trinitron (рис. 4, б, д, е ) 3 різним рівнем коливань колірної температури, але із достатньою стабільністю $(\Delta \mathrm{E}<1)$. Дозволяють відтворювати кольори протягом тривалого терміну приблизно у межах 10-12 днів.

Отже, для забезпечення додрукарської обробки тонових оригіналів на відеосистемах KBC, необхідно здійснювати перевірку колірного охоплення та стабільності кольовідтворення на всій площині екрану для кожного застосованого монітору. До того ж, точність додрукарської обробки залежатиме від періодичності процесів калібрування і профілювання моніторів. Причому для більшості досліджуваних моніторів для досягнення точності на рівні $\Delta \mathrm{E}<1$ у процесах цифрової екранної кольоропроби 

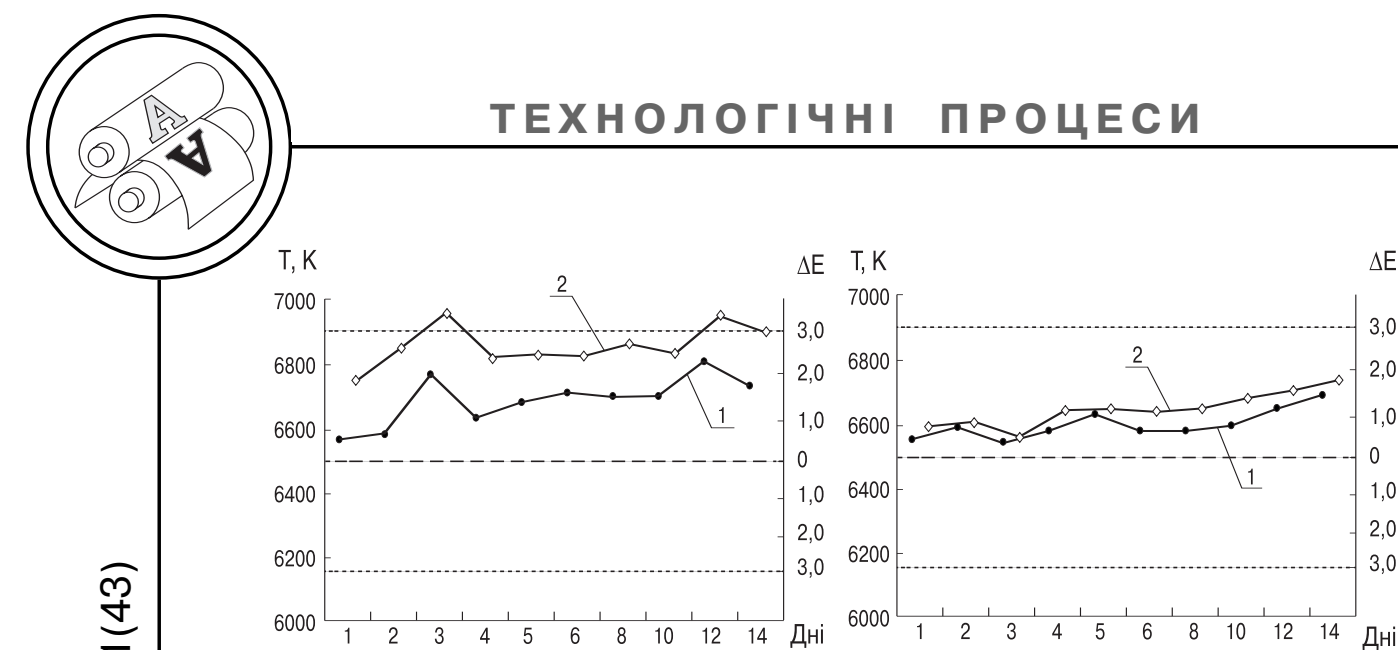

a

б
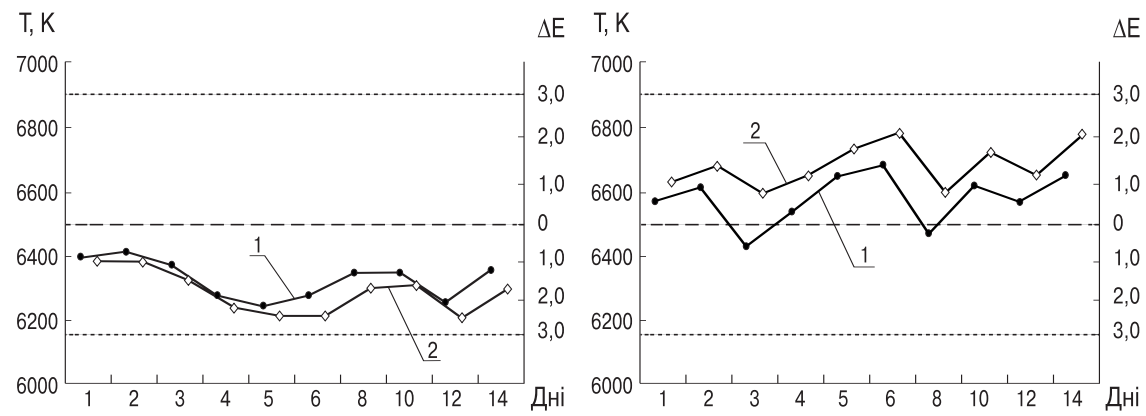

B

$\Gamma$
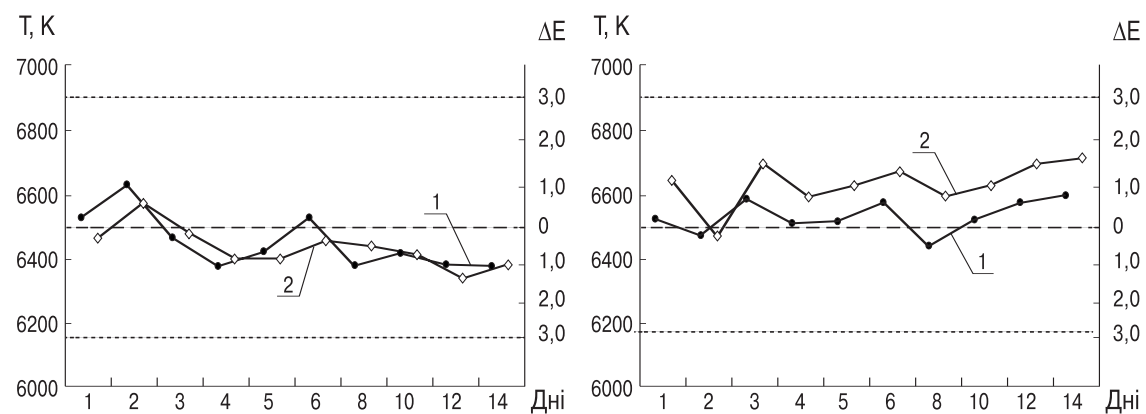

д

e

Рис. 4. Розподіл колірної температури за днями: 1 - значення центральної ділянки; 2 - середнє значення дев'яти ділянок; а - Asus WW202SR (LCD); б — Sony Trinitron (CRT); в - Samsung R530; г — Samsung SyncMaster 2043; д — LG Flatron L 194WS; е — LG Flatron W1942S

періодичність калібрування повинна складати не менше 3-4 дні, замість рекомендованих 1-2 тижнів [10-12]. Щодо максимально допустимої точності на рівні $1<\Delta \mathrm{E}<3$ у процесах тоно- і кольорокорекції, то вона може бути досягнута навіть протягом 1-2 тижнів після останнього калібрування. 


\section{Висновки}

1. На підставі проведеного дослідження встановлено характер впливу основних режимів відеосистеми КВС на якість відтворення кольору тонових оригіналів, який полягає у тому, що зі зростанням колірного охопленням виникає ймовірність незначного підвищення нерівномірності яскравості на екрані монітору.

2. Визначено оптимальний період у межах 3-4 днів для здійснення калібрування для конкретного класу моніторів із забезпеченням стабільного кольоровідтворення на рівні $\Delta \mathrm{E}<1$.

3. Запропоновано перелік рекомендацій для стабілізації процесу додрукарської обробки тонових оригіналів, а саме проведення аналізу колірних властивостей конкретного монітору на основі відповідності його колірної температури, колірного охоплення та рівномірності яскравості, щодо встановленим стандартами вимогам до відеосистеми KBC.

\section{Список використаної літератури}

1. Зоренко Я. В. Дослідження системи «оригінал-відбиток» із визначенням впливу її параметрів на стабільність процесу репродукування плоским офсетним друком / Я. В. Зоренко // Технологія і техніка друкарства. 2013. - № 3(33). - С. 41-48.

2. Букасов М. Цвет под контролем / М. Букасов // PrintPlus. - 2011. № 4(78). - С. 46-48.

3. Кукушкин Д. А. Экранная цветопроба [Електронний ресурс] / Д. А. Кукушкин, Ю. Н. Самарин // Компьюарт. - 2011. - № 2. - Режим доступу : http://www.compuart.ru/article. aspx?id=22034\&iid=1007.

4. Френкель А. Колориметрическая настройка монитора. Теория и практика / А. Френкель, А. Шадрин. - М. : АвгустБорг. - 2005. - 150 с.

5. E. A. Day, L. Taplin, R. S. Berns. Colorimetric Characterization of a Computer-Controlled Liquid Crystal Display, Color Res. Appl. 29, pp. 365-373 (2004). - See more at : http://www.cis.rit.edu/ jxj1770/ DisplayCharacterization/data /displaycharacterization.pdf.

6. Попов А. Проблемы профилирования цветовых устройств : взгляд с позиции X-Rite [Електронний ресурс] // КомпьюАрт. - 2005. - № 8. - Режим доступа : http://www.compuart.ru/article.aspx?id=9096\&iid=380.

7. Антон Самсонов. Калибровка мониторов - от сложного к простому [Электронный ресурс] // Мир ПК. - 2006. - № 04. - Режим доступа : http://www.osp.ru/pcworld/2006/04/1156060.

8. Пахомов С. Если фотография должна быть качественной... [Електронний ресурс] // КомпьютерПресс. - 2009. - № 2. - Режим доступу : http://compress.ru/article.aspx?id=20032.

9. Пахов С. Тестирование 27-дюймовых мониторов [Електронний ресурс] // Компьютерпресс. - 2013. - № 2. - Режим доступу : http://compress.ru/article. aspx?id=23597.

10. Стандарт ISO 12646:2008. Технология полиграфии. Дисплеи для получения цветных пробных изображений. Характеристики и условия для контроля. $-21 \mathrm{c}$.

11. ISO 3664:2000 Viewing conditions - Graphic technology and photography. 
12. ГОСТ Р 52324-2005 (ИСО 13406-2:2001) Эргономические требования к работе с визуальными дисплеями, основанными на плоских панелях. Часть 2 Эргономические требования к дисплеям с плоскими панелями. - Москва : Стандартинформ, 2005.

13. Jeff Yurek. Color Space Confusion [Електронний ресурс]. - Режим доступу : http://dot-color.com/2012/08/14/color-space-confusion.

\section{References}

1. Zorenko la. V. Doslidzhennia systemy «oryhinal-vidbytok» iz vyznachenniam vplyvu yii parametriv na stabilnist protsesu reprodukuvannia ploskym ofsetnym drukom / la. V. Zorenko // Tekhnolohiia i tekhnika drukarstva. 2013. - № 3(33). - S. 41-48.

2. Bukasov M. Cvet pod kontrolem / M. Bukasov // PrintPlus. - 2011. № 4(78). - S. 46-48.

3. Kukushkin D. A. Jekrannaja cvetoproba [Elektronnyi resurs] / D. A. Kukushkin, Ju. N. Samarin // Komp'juart. - 2011. - № 2. - Rezhym dostupu : http://www.compuart.ru/article.aspx?id=22034\&iid=1007.

4. Frenkel' A. Kolorimetricheskaja nastrojka monitora. Teorija i praktika / A. Frenkel', A. Shadrin. - M. : AvgustBorg. - 2005. - $150 \mathrm{~s}$.

5. E. A. Day, L. Taplin, R. S. Berns. Colorimetric Characterization of a Computer-Controlled Liquid Crystal Display, Color Res. Appl. 29, pp. 365-373 (2004). - See more at : http://www.cis.rit.edu/ jxj1770/ Display Characterization/data /displaycharacterization.pdf.

6. Popov A. Problemy profilirovanija cvetovyh ustrojstv : vzgljad s pozicii XRite [Elektronnyi resurs] // Komp'juArt. - 2005. - № 8. - Rezhym dostupu : http://www.compuart.ru/article.aspx?id=9096\&iid=380.

7. Anton Samsonov. Kalibrovka monitorov - ot slozhnogo k prostomu [Jelektronnyj resurs] // Mir PK. - 2006. - № 04. - Rezhim dostupa : http://www.osp.ru/pcworld/2006/04/1156060.

8. Pahomov S. Esli fotografija dolzhna byt' kachestvennoj... [Elektronnyi resurs] // Komp'juterPress. - 2009. - № 2. - Rezhym dostupu : http://compress.ru/article. aspx?id=20032.

9. Pahov S. Testirovanie 27-djujmovyh monitorov [Elektronnyi resurs] // Komp'juterpress. - 2013. - № 2. - Rezhym dostupu : http://compress.ru/ article. aspx?id=23597.

10. Standart ISO 12646:2008. Tehnologija poligrafii. Displei dlja poluchenija cvetnyh probnyh izobrazhenij. Harakteristiki i uslovija dlja kontrolja. $-21 \mathrm{~s}$.

11. ISO 3664:2000 Viewing conditions - Graphic technology and photography.

12. GOST R 52324-2005 (ISO 13406-2:2001) Jergonomicheskie trebovanija k rabote s vizual'nymi displejami, osnovannymi na ploskih paneljah. Chast' 2 Jergonomicheskie trebovanija $\mathrm{k}$ displejam s ploskimi paneljami. - Moskva : Standartinform, 2005.

13. Jeff Yurek. Color Space Confusion [Elektronnyi resurs]. — Rezhym dostupu : http://dot-color.com/2012/08/14/color-space-confusion.
Определен характер влияния основных параметров видеосистемы КИС на качество воспроизведения цвета тоновых оригиналов. Установлен оптимальный период проведения калибровки для конкретного класса мониторов с обеспечением стабильного цветовоспроизведения. 
Предложен перечень рекомендаций для стабилизации процесса калибровки.

Ключевые слова: калибровка монитора, профилирование мониторов, цветовой охват, максимальная яркость, цветовая температура.

The character of the influence of the DTP's video displays basic modes on the quality of the tone originals were considered. The optimal duration of the calibration for a particular class of monitors to ensure a stable color reproduction was determined. The list of recommendations for stabilization at soft proofing process was proposed.

Keywords: monitor calibration, profiling monitors, color gamut, maximum brightness, color temperature.

Рецензент - О. І. Хмілярчук, К.Т.Н., доцент, НТУУ «КП|»

Надійшла до редакції 25.03.14 